\title{
Substâncias guímicas com Atividades Alelopáticas Presentes NAS Folhas de Parkia pendula (Leguminosae) ${ }^{1}$
}

\author{
Chemical Compounds with Allelopathic Activities in Parkia pendula (Leguminosae) Leaves
}

SOUZA FILHO, A.P.S. ${ }^{2}$, FONSECA, M.L. ${ }^{3}$ e ARRUDA, M.S.P. ${ }^{3}$

\begin{abstract}
RESUMO - Os objetivos deste trabalho foram isolar, identificar e caracterizar a atividade alelopática de substâncias químicas produzidas por Parkia pendula. Os efeitos alelopáticos foram avaliados sobre a germinação de sementes e o desenvolvimento da radícula das plantas daninhas malícia (Mimosa pudica) e mata-pasto (Senna obtusifolia). O processo de isolamento das substâncias envolveu a extração com solvente em ordem crescente de polaridade, e a elucidação estrutural foi realizada via Ressonância Magnética Nuclear, espectro de COSY e de HETCOR. Os bioensaios foram desenvolvidos em condições controladas de $25{ }^{\circ} \mathrm{C}$ de temperatura e fotoperíodo de 12 (germinação) e 24 horas (desenvolvimento da radícula). Foram isolados e identificados nas folhas da $P$. pendula os seguintes aleloquímicos: ácido 3,4,5-trimetoxibenzóico (S1), ácido 3,4-dimetoxibenzóico (S2) e o Blumenol A (S3). Comparativamente, S1 e S2 apresentaram maior atividade alelopática. Os efeitos promovidos sobre o desenvolvimento da radícula foram de maior magnitude do que aqueles verificados sobre a germinação das sementes. As substâncias isoladas mostraram baixo potencial inibitório da germinação das sementes, especialmente as sementes de mata-pasto. Os efeitos alelopáticos inibitórios estiveram positivamente associados à concentração das substâncias, embora em alguns casos esses efeitos não tenham correspondido às diferenças estatísticas.
\end{abstract}

Palavras-chave: aleloquímico, inibição, germinação, radícula, sementes.

\begin{abstract}
The objective of this paper was to isolate, identify and characterize the allelopathic activity of chemical compounds produced by Parkia pendula. The allelopathic effects were evaluated on seed germination and radicle elongation of the weeds Mimosa pudica and Senna obtusifolia. The isolation process of the compounds involved the use of solvent in an increasing polarity order for extraction and the structural elucidation was carried out by Nuclear Magnetic Resonance, COPSY's and HETCOR's spectrum. The bioassays were carried out under controlled conditions of $25{ }^{\circ} \mathrm{C}$ of temperature and 12-hour photoperiod for seed germination and 24-hour photoperiod for radicle elongation. The following allelochemicals were isolated and identified in P. pendula's leaves: 3,4,5-trimethoxybenzoic acid (S1), 3,4-dimethoxybenzoic acid (S2) and Blumenol A (S3). Comparatively, S1 and S2 showed greater allelopathic activity. The effects on radicle elongation were greater than those observed on seed germination. The isolated substances showed low inhibition potential on seed germination, especially on S. obtusifolia seeds. The allopathic inhibition effects were positively related to the concentration of the substances, although in some cases, these effects have not corresponded to the statistical differences.
\end{abstract}

Key words: allelochemical, inhibition, germination, radicle, seeds.

Recebido para publicação em 3/5/2005 e na forma revisada em 25/11/2005.

2 Embrapa Amazônia Oriental, Trav. Dr. Enéas Pinheiro, S/N, 66095-100 Belém-PA. ${ }^{3}$ Universidade Federal do Pará - UFPA, Rua Augusto Corrêa 01, 66075-900 Belém-PA. 


\section{INTRODUÇÃO}

A biodiversidade amazônica, pela sua abundância e diversidade de espécies de plantas e microrganismos, pode representar fonte ímpar para a prospecção de novas e importantes fontes químicas para fazer frente ao desafio de se estabelecer novo paradigma de controle efetivo das plantas daninhas, que se enquadre nas exigências da sociedade em relação à preservação da qualidade dos recursos naturais, que não contamine os alimentos da dieta dos animais, em geral, e do homem, em particular, e que seja, ao mesmo tempo, eficiente no controle dessas pragas, proporcionando o desenvolvimento de uma agricultura produtiva e enquadrada nos protocolos de preservação ambiental.

Compostos com propriedades alelopáticas altamente diversificados quimicamente são freqüentemente encontrados nas plantas superiores; a composição e a quantidade desses compostos podem variar com a espécie estudada (Putnam, 1985). Especificamente para as espécies arbóreas, vários esforços foram envidados, nos últimos anos, visando identificar propriedades alelopáticas em espécies com potencial para compor sistemas agroflorestais e silvipastoris tanto no Brasil (Borges et al., 1993; Jacobi \& Ferreira, 1991) como em outros países (Chou, 1992; Gonzáles et al., 1995; Zhang, 1993).

O gênero Parkia é pantropical, com sua maior diversidade na Amazônia, englobando 17 espécies neotropicais. A espécie Parkia pendula, conhecida vulgarmente por "visqueiro", é encontrada na Região Amazônica, porém sua distribuição vai do Espírito Santo à América Central (Ribeiro et al., 1999). É uma espécie arbórea, de dossel, com copa plana e vistosa, com cascas sempre vermelhas. $O$ fato de pertencerem à família Leguminosae desperta interesse agronômico, em face da característica de fixação simbiótica de nitrogênio, de interesse para compor sistemas silvipastoris.

Embora quimicamente pouco se saiba sobre a espécie Parkia pendula, alguns estudos já foram desenvolvidos com outras espécies do gênero, como é o caso de $P$. clappertoniana (Lemmich et al., 1996), P. biglobosa (Tringali et al., 2000) e P. speciosa (Jamaluddin et al., 1995), das quais foram isoladas e identificadas substâncias pertencentes às classes dos flavonóides, triterpenos, esteróides e ésteres derivados do ácido chiquímico. Considerando que essas classes de compostos químicos têm sido associadas à atividade alelopática, há grande possibilidade de que substâncias químicas com atividades alelopáticas estejam presentes em folhas de $P$. pendula.

Os objetivos deste trabalho foram isolar, identificar e caracterizar a atividade alelopática de substâncias químicas produzidas por Parkia pendula.

\section{MATERIAL E MÉTODOS}

\section{Coleta e identificação do material botânico}

A coleta foi realizada na Serra das Andorinhas, no município de São Geraldo do Araguaia, Estado do Pará. Foram coletadas amostras para compor a exsicata e $2,5 \mathrm{~kg}$ de folhas para realização das extrações. O material coletado foi seco inicialmente em condições ambientais e mais tarde em estufa com circulação forçada de ar, por 72 horas, a $40{ }^{\circ} \mathrm{C}$. Em seguida, procedeu-se à trituração em moinho tipo Willey e ao acondicionamento em sacos de plástico.

\section{Procedimentos de isolamento e identificação das substâncias com atividades alelopáticas}

No fluxograma (Figura 1) são apresentadas as diferentes fases dos procedimentos empregados no processo de isolamento das substâncias químicas com atividades alelopáticas. Inicialmente processou-se a extração por percolação, a frio, utilizando-se álcool etílico, na proporção de quatro litros do solvente a cada 12 horas de extração, seguido da concentração em rotavapor Büchi, modelo EL-131. Como resultado do processo, foram obtidos $10,0 \mathrm{~g} \mathrm{de}$ extrato bruto, que foi submetido ao fracionamento em CCVU filtrante, utilizando-se como fase estacionária sílica-gel 70-230 Mesh, desativada com $\mathrm{MeOH} / \mathrm{H}_{2} \mathrm{O}$, na proporção de 1:1 e, como fase móvel, solventes puros e misturas binárias de solventes, com polaridades crescentes, resultando num total de sete frações, como se segue: hexano - 100\% $\left(\mathrm{P}_{1}\right)$; hexano: $\mathrm{CH}_{2} \mathrm{Cl}_{2}-50 \%\left(\mathrm{P}_{2}\right) ; \mathrm{CH}_{2} \mathrm{Cl}_{2}-100 \%\left(\mathrm{P}_{3}\right)$; 


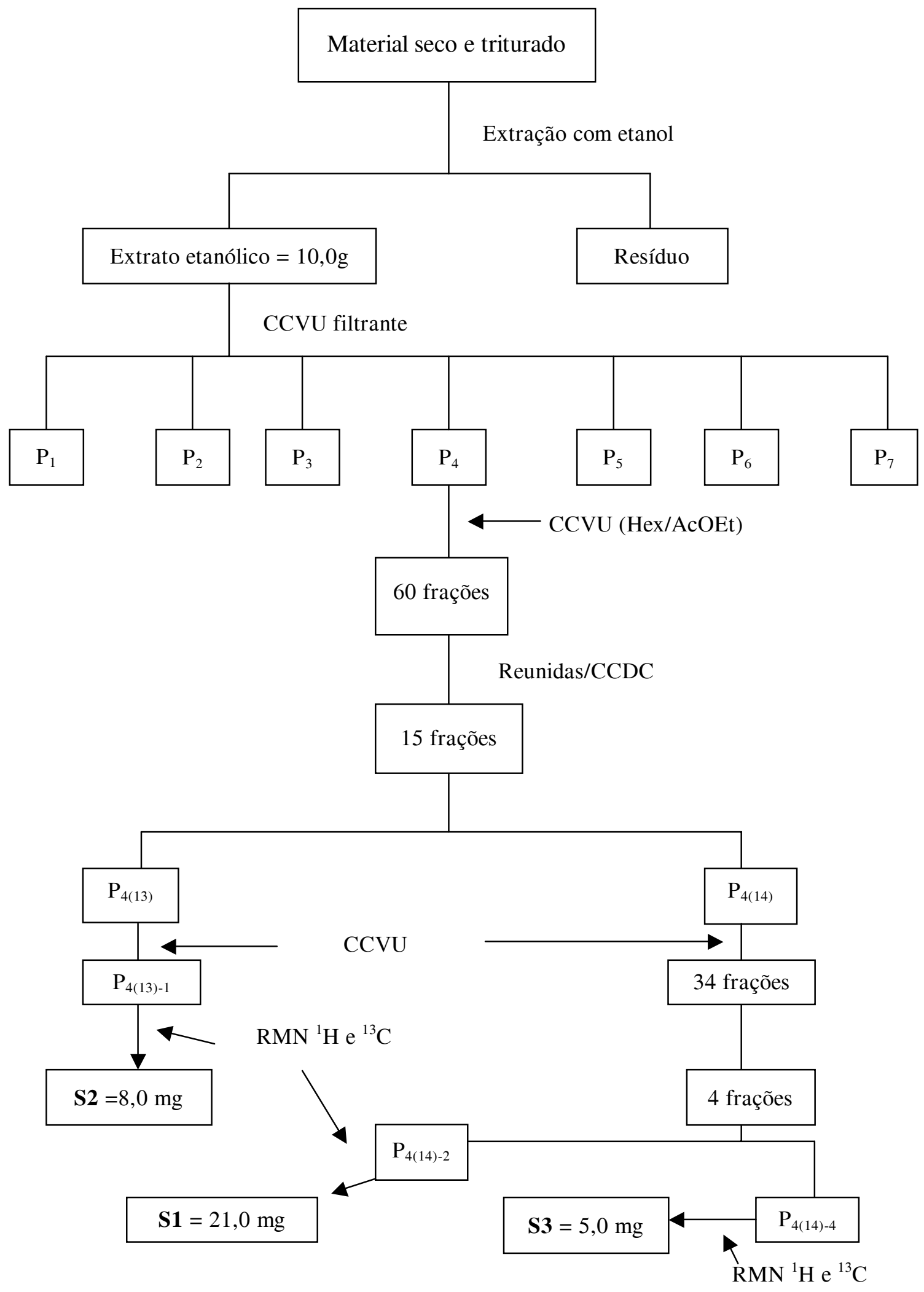

Figura 1 - Fluxograma dos procedimentos para isolamento e identificação de substâncias químicas com atividades alelopáticas, em folhas de P. pendula. 
$\mathrm{CH}_{2} \mathrm{Cl}_{2}$ :AcOEt - 50\% $\left(\mathrm{P}_{4}\right)$; AcOEt - 100\% $\left(\mathrm{P}_{5}\right)$; AcEOt:MeOH - 50\% $\left(\mathrm{P}_{6}\right)$; e MeOH - 100\% $\left(\mathrm{P}_{7}\right)$.

$\mathrm{O}$ resultado do bioensaio de avaliação dessas frações (Figura 2) indicou que as substâncias com atividades alelopáticas estavam nas frações $\mathrm{P}_{4}, \mathrm{P}_{5}$ e $\mathrm{P}_{6}$. A fração $\mathrm{P}_{4}$ foi refracionada em CCVU, utilizando-se como eluentes misturas de hexano e acetato de etila, em gradiente crescente de polaridade, obtendo-se 60 frações, que foram monitoradas, via $\mathrm{CCDC}$, e reunidas em 15 frações. Refracionamentos subseqüentes foram realizados até a obtenção das substâncias químicas puras (Figura 1).

Métodos espectrométricos de Ressonância Magnética Nuclear de RMN ${ }^{1} \mathrm{H}$, RMN ${ }^{13} \mathrm{C}$, NOEDIFF e DEPT, em conjunto com as técnicas bidimensionais COSY ${ }^{1} \mathrm{H} \mathrm{x}{ }^{1} \mathrm{H}, \mathrm{HETCOR}, \mathrm{HMBC}$ e HSQC, foram utilizados na determinação estrutural, juntamente com a comparação com os dados disponíveis na literatura.

\section{Avaliação da atividade alelopática}

1. Bioensaios de germinação: Foram desenvolvidos em condições controladas de $25{ }^{\circ} \mathrm{C}$ de temperatura constante e fotoperíodo de 12 horas. A germinação foi monitorada em períodos de dez dias, com contagens diárias e eliminação das sementes germinadas. Foram consideradas sementes germinadas aquelas que apresentavam extensão radicular igual ou superior a 2,0 mm (Juntila, 1976; Duram \& Tortosa, 1985). Em cada placa de Petri de $9,0 \mathrm{~cm}$ de diâmetro, forrada com uma folha de papel-filtro qualitativo, foram adicionadas 20 sementes.

2. Bioensaios de desenvolvimento da radícula: Foram realizados em condições controladas de $25{ }^{\circ} \mathrm{C}$ de temperatura constante e fotoperíodo de 24 horas. Em placas de Petri de $9,0 \mathrm{~cm}$ de diâmetro, forradas com papelfiltro qualitativo, foram adicionadas três sementes pré-germinadas, com aproximadamente três dias de germinação. Ao final do período de dez dias de crescimento, media-se o comprimento da radícula.

\section{Procedimentos experimentais adicionais}

A concentração usada na avaliação dos extratos brutos foi de $0,5 \%$ (p/v). Na avaliação da atividade das substâncias químicas isoladas foram empregadas as concentrações de $5,10,15$ e $20 \mathrm{mg} \mathrm{L}^{-1}$, tendo como eluente o metanol. Em todos os bioensaios, adicionou-se o volume de $3,0 \mathrm{~mL}$ da fração ou da substância avaliada, por placa de Petri. O material foi adicionado apenas uma vez, quando do início do experimento, sendo, a partir de então, adicionada apenas água destilada, sempre que se fazia necessário. Após a adição dos extratos brutos e das substâncias, deixava-se evaporar o solvente e adicionava-se o mesmo volume de água destilada, mantendo-se, dessa forma, as concentrações originais.

As plantas daninhas utilizadas como receptoras foram Mimosa pudica (malícia) e Senna obtusifolia (mata-pasto). As sementes dessas plantas foram coletadas em áreas de fazendas particulares, localizadas no município de Castanhal-PA. Elas passaram por processo de limpeza e foram tratadas com ácido sulfúrico concentrado, com vistas à superação da dormência (Souza Filho et al., 1998).

\section{Análise estatística}

O delineamento experimental para todos os bioensaios foi o inteiramente casualizado, em modelo hierárquico, com dois fatores e três repetições (ver modelo a seguir). Procedeu-se à análise de variância dos dados obtidos pelo teste $\mathrm{F}$, e as médias foram comparadas pelo teste de Tukey (5\%). Os dados foram analisados pelo programa estatístico SAS (Sas, 1989).

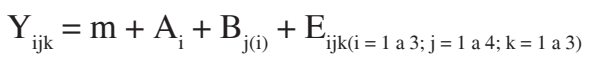

em que $Y_{\mathrm{ijk}}=$ variável de resposta - germinação e desenvolvimento da radícula; $\mathrm{m}=$ média geral; $\mathrm{A}_{\mathrm{i}}=$ efeito do fator $\mathrm{A}$ - planta daninha; $\mathrm{B}_{\mathrm{j}(\mathrm{i})}=$ efeito do fator $\mathrm{B}$ - concentração; e $\mathrm{E}_{\mathrm{ij \textrm {k }}}=$ erro experimental.

\section{RESULTADOS E DISCUSSÃO}

\section{Substâncias químicas isoladas e identificadas}

A avaliação inicial realizada nas frações obtidas a partir do extrato etanólico mostrou que as substâncias químicas com atividade alelopática se encontravam nas frações $\mathrm{P}_{4}, \mathrm{P}_{5}$ 
e $\mathrm{P}_{6}$, indicando que as substâncias envolvidas na atividade alelopática apresentavam polaridade entre o diclorometano e o metanol (Figura 2). Em virtude de a fração $\mathrm{P}_{4}$ ter sido obtida com uma mistura de 50:50 de diclorometano e acetato de etila, sendo por isso mesmo mais fácil de fracionar, em relação às outras frações mais polares, e considerandose ainda a intensidade da inibição efetivada sobre a germinação das sementes das plantas daninhas malícia e mata-pasto, optou-se por essa fração para dar continuidade ao processo de isolamento das substâncias com atividades alelopáticas. Em razão da baixa quantidade de material obtida na fração $\mathrm{P}_{1}$, não foi possível testar essa fração.

Pelo esquema apresentado no fluxograma, observa-se que a partir da fração $\mathrm{P}_{4(13)}$, via CCVU, utilizando-se misturas de hexano e acetato de etila, em polaridade crescente, foi isolada a substância $\mathrm{S} 2$. Da fração $\mathrm{P}_{4(14)}$, via CCVU, empregando-se como eluentes mistura de hexano e acetato de etila, em ordem de polaridade crescente, foram obtidas as substâncias S1 e S3.

O espetro de RMN de ${ }^{1} \mathrm{H}$ da substância $\mathrm{S} 1$ (Tabela 1) indicou a existência de três sinais singletos, sendo um integrado a dois hidrogênios em $\delta 7,36$, atribuído a dois hidrogênios quimicamente semelhantes, ligados ao anel aromático, e um conjunto formado por dois singletos, integrando para nove hidrogênios em $\delta 3,92$ e 3,93, referentes a três grupos metoxila ligados ao anel aromático, sendo dois deles quimicamente equivalentes. Os dados do espectro de RMN de ${ }^{13} \mathrm{C}$ (Tabela 1) dessa substância indicaram, além do sinal da carbonila de ácido e da metoxila orto-di-substituída, sinais em $\delta 56,3$, referente às duas metoxilas equivalentes das posições $3 / 5 ; \delta 107,5$, referente aos dois carbonos $\mathrm{CH}$ quimicamente semelhantes das posições $2 / 6$; e três sinais em $\delta 124,140$ e 153, assinalados, respectivamente, a um carbono aromático totalmente substituído da posição 1, um carbono aromático oxidado da posição 4 e dois carbonos aromáticos oxidados e equivalentes das posições $3 / 5$. O conjunto dessas informações espectrais permite indicar a substância S1 como o ácido 3,4,5-trimetoxibenzóico - ver estrutura na Figura 3. Em recentes pesquisas, essa substância apresentou atividade antimicrobiana, inibindo o crescimento de Staphylococus aureus (Besigmano et al., 2000).

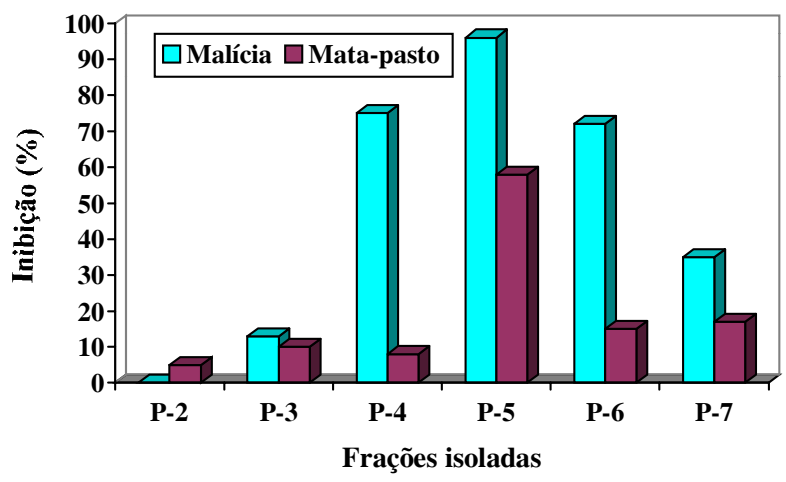

Figura 2 - Efeitos potencialmente alelopáticos de frações obtidas do extrato etanólico sobre a germinação de sementes de plantas daninhas. Dados expressos em percentual de inibição em relação ao tratamento testemunha (água destilada).

Tabela 1 - Dados de RMN de ${ }^{1} \mathrm{H}$ (ppm, $\left.\mathrm{CD}_{3} \mathrm{OD}, 300 \mathrm{MHz}\right)$ e de ${ }^{13} \mathrm{C}\left(\mathrm{ppm}, \mathrm{CD}_{3} \mathrm{OD}, 75 \mathrm{MHz}\right)$ para a substância $\mathbf{S 1}$

\begin{tabular}{|c|c|c|}
\hline Posição & ${ }^{1} \mathrm{H}$ & ${ }^{13} \mathrm{C}$ \\
\hline 1 & - & 124,0 \\
\hline $2 / 6$ & $7,36(s)$ & 107,5 \\
\hline $3 / 5$ & - & 153,0 \\
\hline 4 & - & 143,0 \\
\hline $\mathrm{COOH}$ & - & 170,2 \\
\hline OMe-3/5 & $3,92(s)$ & 56,3 \\
\hline OMe-4 & $3,93(\mathrm{~s})$ & 60,9 \\
\hline
\end{tabular}

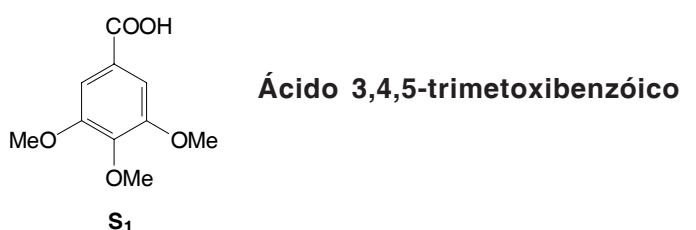

$\mathrm{s}_{1}$

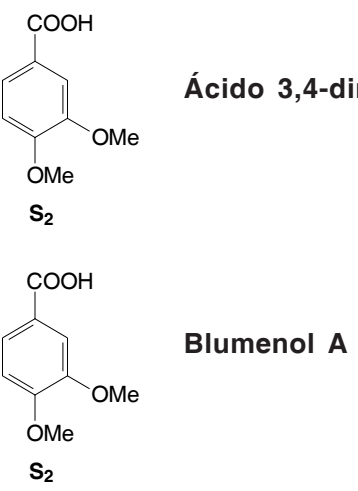

Figura 3 - Estruturas químicas das substâncias isoladas das folhas de P. pendula.

Planta Daninha, Viçosa-MG, v. 23, n. 4, p. 565-573, 2005 
O espectro de RMN de ${ }^{1} \mathrm{H}$ da substância S2 (Tabela 2) apresentou três sinais na região de hidrogênio aromáticos e dois sinais referentes a grupos metoxila, ligados a carbono aromático. Os sinais observados foram: um dupleto integrado para um hidrogênio, centrado em $\delta 7,75(J=8,7$ e $1,8 \mathrm{~Hz})$, referente ao hidrogênio H-6; um dupleto integrado para um hidrogênio em $\delta 7,58(J=1,8 \mathrm{~Hz})$, assinalado ao hidrogênio $\mathrm{H}-2$; e um dupleto integrado para um hidrogênio em $\delta 6,91(\mathrm{~J}=8,7 \mathrm{~Hz})$, atribuído ao $\mathrm{H}-5$. Esses sinais se correlacionam de forma orto-meta, orto e meta, respectivamente, o que é confirmado pelo experimento de correlação homonuclear COSY ${ }^{1} \mathrm{H} \times{ }^{1} \mathrm{H}$.

Tabela 2 - Dados de RMN de ${ }^{1} \mathrm{H}$ (ppm, $\mathrm{CD}_{3} \mathrm{OD}, 300 \mathrm{MHz}$ ) e de ${ }^{13} \mathrm{C}\left(\mathrm{ppm}, \mathrm{CD}_{3} \mathrm{OD}, 75 \mathrm{MHz}\right)$ para a substância $\mathbf{S 2}$

\begin{tabular}{|c|c|c|}
\hline Posição & ${ }^{1} \mathrm{H}$ & ${ }^{13} \mathrm{C}$ \\
\hline 1 & - & 120,6 \\
\hline 2 & $7,58 \mathrm{~d}(J=1,8 \mathrm{~Hz})$ & 111,4 \\
\hline 3 & - & 147,7 \\
\hline 4 & - & 152,7 \\
\hline 5 & $6,91 \mathrm{~d}(J=8,7 \mathrm{~Hz})$ & 109,3 \\
\hline 6 & $7,75 \mathrm{dd}(J=8,7 \mathrm{e} 1,8 \mathrm{~Hz})$ & 123,5 \\
\hline COOH & - & 189,7 \\
\hline OMe-3 & $3,93(s)$ & $55,0^{\mathrm{c}}$ \\
\hline OMe-4 & $3,94(s)$ & $55,1^{\mathrm{c}}$ \\
\hline
\end{tabular}

${ }^{\mathrm{C}}$ sinais interconvertidos.

Observou-se, ainda, um conjunto formado por dois singletos integrados para seis hidrogênios, atribuídos a dois grupos metoxila ligados ao anel aromático, em $\delta 3,95$ e 3,94. O assinalamento desses dois grupos foi determinado a partir do experimento de NOEDIFF, o qual mostrou efeito NOE entre o sinal irradiado em $\delta 6,91$ da posição 5, o sinal duplo dupleto em $\delta 7,75$ da posição 6 e o sinal singleto em $\delta 3,95$, o qual foi atribuído ao grupo metoxila da posição 4; conseqüentemente, o sinal em $\delta 3,94$ foi assinalado para o grupo metoxila da posição 3 .

O espectro de RMN de ${ }^{13} \mathrm{C}$ da substância S2 (Tabela 2) indicou nove sinais referentes aos nove carbonos da estrutura da substância. $\mathrm{O}$ conjunto desses dados, associado às informações disponiveis na literatura (Machida \& Kikuchi, 1996), permitiu identificar a substância S2 como o ácido 3,4-dimetoxibenzóico, conhecido vulgarmente pelo nome de ácido verátrico, cuja estrutura é apresentada na Figura 3.

A análise dos dados espectrais de RMN de ${ }^{1} \mathrm{H}$ da substância S3 (Tabela 3) revelou sinais na região de hidrogênio olefínicos, carbinólicos e alifáticos. Alguns desses sinais foram: um duplo dupleto em $\delta 5,87(J=15,6$ e $6,0 \mathrm{~Hz})$ e um dupleto em d 5,77 ( $J=15,6 \mathrm{~Hz})$, indicando uma ligação $-\mathrm{HC}=\mathrm{CH}$ - com os hidrogênios em relação trans, observada pelos valores da constante de acoplamento $(J=15,6 \mathrm{~Hz})$; um quinteto em $\delta 4,41(J=6,0 \mathrm{~Hz}))$; e um sinal dupleto referente a uma metila ligada em $\delta 1,30(J=6,0 \mathrm{~Hz})$.

Tabela 3 - Dados de RMN de ${ }^{1} \mathrm{H}$ (ppm, $\mathrm{CD}_{3} \mathrm{OD}, 300 \mathrm{MHz}$ ) e de ${ }^{13} \mathrm{C}\left(\mathrm{ppm}, \mathrm{CD}_{3} \mathrm{OD}, 75 \mathrm{MHz}\right)$ para a substância $\mathbf{S 3}$

\begin{tabular}{|c|c|c|}
\hline Posição & ${ }^{1} \mathrm{H}$ & ${ }^{13} \mathrm{C}$ \\
\hline 1 & - & 41,1 \\
\hline 2 & $\begin{array}{l}2,24 \mathrm{~d}(J=17,0 \mathrm{~Hz}) \\
2,45 \mathrm{~d}(J=17,0 \mathrm{~Hz})\end{array}$ & 49,7 \\
\hline 3 & - & 198,1 \\
\hline 4 & $5,90 \mathrm{~d}(J=1,2 \mathrm{~Hz})$ & 126,8 \\
\hline 5 & - & 162,9 \\
\hline 6 & - & 79,0 \\
\hline 7 & $5,77 \mathrm{~d}(J=15,6 \mathrm{~Hz})$ & 135,7 \\
\hline 8 & $5,87 \mathrm{dd}(J=15,6$ e $6,0 \mathrm{~Hz})$ & 128,9 \\
\hline 9 & $4,41 \mathrm{qt}(J=6,0 \mathrm{~Hz})$ & 67,9 \\
\hline 10 & $1,29 \mathrm{~d}(J=6,0 \mathrm{~Hz})$ & 23,7 \\
\hline 11 & $0,99(s)$ & 22,9 \\
\hline 12 & $1,07(s)$ & 24,0 \\
\hline 13 & $1,89 \mathrm{~d}(J=1,2 \mathrm{~Hz})$ & 18,9 \\
\hline
\end{tabular}

A análise do espectro de correlação homonuclear COSY ${ }^{1} \mathrm{H} \mathrm{x}{ }^{1} \mathrm{H}$ indicou correlações entre todos os sinais mencionados, mostrando que os hidrogênios estão acoplados entre si, caracterizando um grupo do tipo $-\mathrm{CH}=\mathrm{CH}-$ $\mathrm{CHOH}-\mathrm{CH}_{3}$ ligado a um carbono totalmente substituído, sugerindo uma cadeia lateral. Foram observados, ainda, um dupleto centrado em $\delta 5,90(\mathrm{~J}=1,2 \mathrm{~Hz})$, atribuído a um hidrogênio olefínico, que, segundo o espectro de COSY $1 \mathrm{H} \times 1 \mathrm{H}$, está acoplado ao sinal da metila, sobre dupla em $\delta 1,89(J=1,2 \mathrm{~Hz})$; dois dupletos centrados em $\delta 2,24$ e $2,45(J=17,0 \mathrm{~Hz})$, atribuído a dois hidrogênios metilênicos em acoplamento geminal; e dois singletos em $\delta 0,99$ e 1,07, atribuídos a dois grupos metílicos ligados a carbonos $s p^{3}$, totalmente substituído. 
Analisando o espectro de $\mathrm{RMN}{ }^{13} \mathrm{C}$ (Tabela 3), observaram-se 13 sinais, sendo o padrão de hidrogenação determinado via HSQC. Os sinais de ${ }^{13} \mathrm{C}$ que caracterizaram a substância são: um sinal em $\delta 201,4$, relacionado ao carbono de carbonila em um anel cicloexano; um sinal em $\delta 167,6$, atribuído a um carbono olefínico totalmente substituído; três sinais em $\delta 136,6,130,1$ e 127,1, relativos aos três carbonos $\mathrm{CH}$ olefínicos; um sinal em $\delta 80,0$, atribuído a um carbono oxidado, totalmente substituído; um sinal em $\delta 68,7$, assinalado para um carbono oximetínico; um sinal de carbono metilênico vizinho à carbonila em $\delta 50,7$; um sinal de carbono totalmente substituído em $\delta 42,4$; e quatro sinais referentes a quatro metilas em $\delta 24,5 ; 23,8 ; 23,5$; e 19,6 .

O conjunto dessas informações, associado aos dados da literatura (Gonzáles et al., 1994), permitiu concluir que a substância S3 tratase do derivado carotenóide Blumenol A, cuja estrutura da substância é apresentada na Figura 3.

\section{Análise da atividade alelopática das três substâncias isoladas e identificadas}

A intensidade dos efeitos sobre a germinação das sementes das plantas daninhas malícia e mata-pasto variou em função da substância, da concentração desta e da espécie de planta daninha utilizada como indicadora (Tabela 4). Considerando-se os efeitos promovidos nas concentrações extremas, 5,0 e 20,0 $\mathrm{mg} \mathrm{L}^{-1}$, a tendência observada foi de aumentos na inibição da germinação das sementes das duas espécies de plantas daninhas com o incremento da concentração da substância, embora, em alguns casos, esses aumentos não tenham sido estatisticamente diferentes (p>0,05). Em concentrações de 5,0 e $10,0 \mathrm{mg} \mathrm{L}^{-1}$ as inibições observadas ou foram extremamente baixas ou não existiram.

Comparativamente, malícia e mata-pasto apresentaram graus diferentes de respostas às três substâncias. Para mata-pasto, não foram observados efeitos inibitórios da substância S1 nas concentrações testadas, e para as demais substâncias as inibições ou não existiram ou foram baixas, com a máxima inibição não ultrapassando os 10,0\%. Para malícia, os efeitos promovidos pela substância S3 foram, também, extremamente baixos, não ultrapassando os 7,0\%. Para as substâncias S1 e S2 os efeitos foram mais expressivos, atingindo 33,0\% para os efeitos efetivados pela substância S1 e 17,0\% para a substância S2. Contudo, esses efeitos podem ser considerados baixos quando se consideram os efeitos promovidos por outras substâncias, sobre essas mesmas plantas daninhas, em concentrações inferiores, como é o caso do ácido $p$-cumárico (Souza Filho et al., 2005).

A exemplo dos resultados obtidos acerca da germinação das sementes, os efeitos sobre o desenvolvimento da radícula das duas plantas daninhas também variaram em função da substância, da concentração e da planta daninha (Tabela 5). A intensidade das inibições foi positivamente relacionada com a concentração, sendo os efeitos mais intensos observados na concentração de $20,0 \mathrm{mg} \mathrm{L}^{-1}$, independentemente da espécie de planta daninha e da substância analisada, embora esses aumentos não tenham correspondido, em alguns casos, a diferenças estatísticas. Ao contrário do observado no bioensaio de germinação de sementes, o desenvolvimento da radícula do mata-pasto tendeu a ser mais intensamente inibido pelas substâncias do que o da malícia.

Tabela 4 - Efeitos de três substâncias químicas sobre a germinação de sementes de plantas daninhas. Dados expressos em percentual de inibição, em relação ao tratamento testemunha (água destilada)

\begin{tabular}{|c|c|c|c|}
\hline $\begin{array}{c}\text { Substância } \\
\text { Isolada }\end{array}$ & Concentração & \multicolumn{2}{|c|}{ Planta Daninha } \\
\cline { 2 - 4 } & $\left(\mathrm{mg} \mathrm{L}^{-1}\right)$ & Malícia & Mata-pasto \\
\hline \multirow{4}{*}{ S1 } & 5,0 & $0,0 \mathrm{Da}$ & $0,0 \mathrm{Aa}$ \\
& 10,0 & $13,0 \mathrm{Ca}$ & $0,0 \mathrm{Ab}$ \\
& 15,0 & $25,0 \mathrm{Ba}$ & $0,0 \mathrm{Ab}$ \\
\cline { 2 - 4 } & 20,0 & $33,0 \mathrm{Aa}$ & $0,0 \mathrm{Ab}$ \\
\hline \multirow{4}{*}{ S2 } & 5,0 & $0,0 \mathrm{Ca}$ & $0,0 \mathrm{Ba}$ \\
& 10,0 & $0,0 \mathrm{Ca}$ & $0,0 \mathrm{Ba}$ \\
\cline { 2 - 4 } & 15,0 & $12,0 \mathrm{Ba}$ & $0,0 \mathrm{Bb}$ \\
\cline { 2 - 4 } & 20,0 & $17,0 \mathrm{Aa}$ & $10,0 \mathrm{Ab}$ \\
\hline \multirow{4}{*}{ S3 } & 5,0 & $0,0 \mathrm{Ba}$ & $0,0 \mathrm{Ba}$ \\
& 10,0 & $5,0 \mathrm{Aa}$ & $0,0 \mathrm{Bb}$ \\
& 15,0 & $5,0 \mathrm{Ab}$ & $8,0 \mathrm{Aa}$ \\
\cline { 2 - 4 } & 20,0 & $7,0 \mathrm{Aa}$ & $9,0 \mathrm{Aa}$ \\
\hline
\end{tabular}

Médias seguidas de letras iguais, maiúsculas na coluna e minúsculas na linha, para cada substância, não diferem pelo teste de Tukey ( $p>0,05)$.

Planta Daninha, Viçosa-MG, v. 23, n. 4, p. 565-573, 2005 
Tabela 5 - Efeitos de três substâncias químicas sobre o desenvolvimento da radícula de plantas daninhas. Dados expressos em percentual de inibição, em relação ao tratamento testemunha (água destilada)

\begin{tabular}{|c|c|c|c|}
\hline \multirow{2}{*}{$\begin{array}{c}\text { Substância } \\
\text { Isolada }\end{array}$} & Concentração & \multicolumn{2}{|c|}{ Planta Daninha } \\
\cline { 2 - 4 } & $\left(\mathrm{mg} \mathrm{L}^{-1}\right)$ & Malícia & Mata-pasto \\
\hline \multirow{4}{*}{ S1 } & 5,0 & $8,0 \mathrm{Da}$ & $4,0 \mathrm{Db}$ \\
& 10,0 & $26,0 \mathrm{Ca}$ & $12,0 \mathrm{Cb}$ \\
& 15,0 & $32,0 \mathrm{Ba}$ & $27,0 \mathrm{Bb}$ \\
\cline { 2 - 4 } & 20,0 & $40,0 \mathrm{Aa}$ & $41,0 \mathrm{Aa}$ \\
\hline \multirow{4}{*}{ S2 } & 5,0 & $3,0 \mathrm{Db}$ & $16,0 \mathrm{Da}$ \\
& 10,0 & $12,0 \mathrm{Cb}$ & $30,0 \mathrm{Ca}$ \\
& 15,0 & $20,0 \mathrm{Bb}$ & $48,0 \mathrm{Ba}$ \\
& 20,0 & $23,0 \mathrm{Ab}$ & $55,0 \mathrm{Aa}$ \\
\hline \multirow{4}{*}{ S3 } & 5,0 & $3,0 \mathrm{Ca}$ & $2,0 \mathrm{Da}$ \\
& 10,0 & $5,0 \mathrm{Ba}$ & $5,0 \mathrm{Ca}$ \\
\cline { 2 - 4 } & 15,0 & $7,0 \mathrm{Ba}$ & $7,0 \mathrm{Ba}$ \\
\cline { 2 - 4 } & 20,0 & $12,0 \mathrm{Aa}$ & $13,0 \mathrm{Aa}$ \\
\hline
\end{tabular}

Médias seguidas de letras iguais, maiúsculas na coluna e minúsculas na linha, para cada substância, não diferem pelo teste de Tukey $(\mathrm{p}>0,05)$.

Conquanto o modelo proposto não permitisse a comparação dos efeitos entre as substâncias, os dados mostram que a substância $\mathbf{S 1}$ foi a que promoveu as inibições mais intensas sobre a germinação das sementes (Tabela 4), sendo a substância $\mathbf{S 3}$ a de menor atividade alelopática inibitória. Os efeitos sobre o desenvolvimento da radícula (Tabela 5) foram equivalentes para as substâncias $\mathbf{S 1}$ e S2, que foram superiores às inibições promovidas pela substância S3. Considerando a magnitude das inibições promovidas sobre a germinação das sementes (Tabela 4) e o desenvolvimento da radícula (Tabela 5), verifica-se que as inibições mais intensas foram de $17,0 \%$, sobre a germinação das sementes, e da ordem de $41,0 \%$, sobre o desenvolvimento da radícula, indicando que este último é um parâmetro mais sensivel aos efeitos alelopáticos das três substâncias químicas isoladas das folhas da espécie $P$. pendula.

$P$. pendula é uma leguminosa arbórea e, portanto, com potencial para fixação de nitrogênio. Essa é uma característica desejável na escolha das espécies arbóreas para compor sistemas silvipastoris. O fato de essa espécie produzir substâncias com atividade alelopática se constitui em adicional vantagem para esses sistemas de exploração. Outras espécies similares têm sido estudadas, identificando-se suas propriedades alelopáticas, como é o caso de Vouacapoua americana, conhecida regionalmente pelo nome de acapu (Souza Filho \& Alves, 2000), e Tachigali mymercophila, conhecida regionalmente por tachi-preto (Lôbo, 2004).

A utilização de espécies arbóreas com essas propriedades assume aspectos ecológico e ambiental importantes, em face da possibilidade de os aleloquímicos produzidos serem liberados para o ambiente pelas diferentes formas reconhecidas pela ciência, como lixiviação, exsudação radicular, volatilização e decomposição (Rice, 1987; Rodrigues et al., 1993), afetando, como conseqüência, o padrão e a densidade da vegetação circunvizinha (Smith, 1989; Smith \& Martin, 1994), quer pela redução da germinação das sementes, quer pela redução do potencial de competição das plantas daninhas, via redução do desenvolvimento das plantas. A principal conseqüência desses aspectos é a formação de estandes puros de gramíneas forrageiras, com conseqüente aumento da produtividade e da longevidade da pastagem cultivada e redução no uso de agroquímicos.

\section{LITERATURA CITADA}

BESIGMANO, G. et al. Antimicrobial activity of Mtracarpus scaber extract and isolated constituents. Letter Appl. Microbiol., v. 30, n. 2, p. 105-108, 2000.

BORGES, E. E. L.; LOPES, E. S.; SILVA, G. F. Avaliação de substâncias alelopáticas em vegetação de uma floresta secundária. 1- Árvores. R. Árvore, v. 17, n. 1, p. 69-84, 1993.

CHOU, C. H. Allelopathy on relation to agriculture productivity in Taiwan: problem and prospects. In: RIZVI, S. J. H.; RIZVI, V. (Eds.) Allelopathy. New York: Chapmam \& Holl, 1992. p. 179-203.

DURAM, J. M.; TORTOSA, M. E. The effect of mechanical and chemical scarification on germination of charlock

(Sinapsis arvensis L.) seeds. Seed Sci. Technol., v. 13, n. 1, p. 155-163, 1985.

GONZÁLES, L.; SOUTO, X. C.; REIGOSA, M. J. Allelopathic effects of Acacia melanoxylon R. Br. Phyloides during their decomposition. For. Ecol. Manag., v. 77, n. 1-3, p. 53-63, 1995.

GONZÁLES, A. G. et al. 4,5-Dihydroblumenol A, a new nor-isoprenoid from Perrottetia multiflora. J. Nat. Prod., v. 57, n. 3, p. 400-402, 1994. 
JACOBI, U. S.; FERREIRA, A. G. Efeitos alelopáticos de Mimosa bimicronata (DC) OK. sobre espécies cultivadas. Pesq. Agropec. Bras., v. 26, n. 7, p. 935-943, 1991.

JAMALUDDIN, F.; MOHAMED, S.; LAJIS, M. N. Hypoglycaemic effect of stigmast-4-en-3-one from Parkia speciosa empty pods. Food Chem., v. 54, p. 9-13, 1995.

JUNTILA, O. Seed and embryo germination in S. vulgaris and $S$. reflexa as affected by temperature during seed development. Physiol. Plant., v. 29, p. 264-268, 1976.

LEMMICH, E. et al. 5-Deoxyflavona from Parkia clappertoniana. Phytochem., v. 42, n. 4, p. 1011-1013, 1996.

LÔBO, L. T. Estudos das propriedades alelopáticas de plantas: investigação de aleloquímicos de Tachigali myrmecophyla (leguminosa). 2004. 134 f. Dissertação (Mestrado em Química) - Universidade Federal do Pará, Belém, 2004.

MACHIDA, K.; KIKUCHI, M. Norisoprenoids from Viburnum dilatatum. Phytochemistry, v. 41, n. 5, p. 1333-1336, 1996.

PUTNAM, A. R. Weed allelopathy. In: DUKE, S. O. (Ed.) Weed phisiology, Florida: CRS Press, 1985. p. 131-155.

RIBEIRO, J. E. L. S. et al. Flora da Reserva Duck: Guia de identificação das plantas vasculares de uma floresta de terrafirme na Amazônia Central. Manaus: INPA, 1999. 391 p.

RICE, E. L. Allelopathy: an overview. In: WALLER, G. R. (Ed.) Allelochemical, role in agriculture and forestry. Washington: American Chemical Society, 1987. p. 7-22. (ACS. Symposium Series, 330).
RODRIGUES, L. R. A.; ALMEIDA, A. R. P.; RODRIGUES, T. J. D. Alelopatia em forrageiras e pastagens. In: SIMPÓSIO SOBRE ECOSSISTEMAS DE PASTAGENS, 2., 1993. Jaboticabal. Anais... Jaboticabal: FUNEP/FCAV, 1993. p. $100-129$.

SMITH, A. E. The potential allelopathic characteristics of bitter sneezeweed (Helenium amarum). Weed Sci., v. 37, p. $665-669,1989$.

SMITH, A. E.; MARTIN, D. L. Allelopathic characteristics of thrre cool-season grass in the forage ecosystems. Agron. J., v. 8, n. 2, p. 243-246, 1994.

SOUZA FILHO, A. P. S.; ALVES, S. M. Potencial alelopático de plantas de acapu (Vouacapoua americana): efeitos sobre plantas daninhas de pastagens. Planta Daninha, v. 18, n. 3, p. 435-441, 2000.

SOUZA FILHO, A. P. S.; DUTRA, S.; SILVA, M. A. M. M. Métodos de superação da dormência de sementes de plantas daninhas de pastagens cultivadas da Amazônia. Planta Daninha, v. 16, n. 1, p. 2-11, 1998.

SOUZA FILHO, A. P. S.; PEREIRA, A. A. G.; BAYMA, J. C. Aleloquímico produzido pela gramínea forrageira Brachiaria humidicola. Planta Daninha, v. 23, n. 1, p. 25-32, 2005.

STATISTICAL ANALYSIS SYSTEM - SAS. User's guide. Version 6.4. North Caroline: 1989. 846 p.

TRINGALI, C.; SPATAFORA, C.; LONGO, O. D. Bioactive constituents of the bark of Parkia biglobosa. Fitoterapia, v. 71, p. 118-125, 2000.

ZHANG, Q. Potential role of allelopathy in the soil and the decomposition root of chinese-fir replant woodland. Plant Soil, v. 151, n. 2, p. 205-209, 1993. 